ascertained with any certainty. Probably the wretched condition of the patient before the operation was a contributing factor, as it left no reserve force properly to combat the shock of the operation and to produce a healing reaction in the wound and so to prevent the continual loss of the cerebro-spinal fluid.

The case was a failure both clinically and scientifically. There was no doubt that the tinnitus was present, though diminished, for several days after the operation and it is doubtful if it really ever subsided. Taking into consideration the degeneration described by Dr. Buzzard the continuance of the tinnitus must be attributed to one of two causes : (1) that the noises are central in origin ; or (2) that the causes of the tinnitus originate in the cochlea and the impulses by which they become apparent are conveyed to the brain by the cochlear nerve (the vestibular nerve was completely degenerated).

\section{A NEW METHOD OF DEMONSTRATING THE LARYNGEAL IMAGE AND INTRA- LARYNGEAL OPERATIONS.}

BY EUGENE S. YONGE, M.D. EDIN.,

GONORARY ASSISTANT PHYSICIAN TO THE MANCHESTER HOSPITAL FOR CONSUMPTION AND DISEASES OF THE THROAT.

THE practical study of laryogology appears to have been entered upon-at any rate in this country-by a comparatively small number of the profession outside those actually engaged with the subject as a specialty. The acquisition of the art of laryngoscopy has not been looked upon by the student as necessary for his academic salvation and it has therefore had a tendency to be regarded in the light of a supererogatory work. This circumstance, together with the appreciable amount of time and practical experience required to gain dexterity in laryngeal and intralaryngeal work, and the relatively infrequent occurrence of such cases in general practice, may have been responsible to some extent for the limitation of interest. But there is also the fact that the clinical demonstration of laryngeal cases, whether in the class room or at general medical meetings, has very commonly proved unsatisfactory and cases have failed to arouse the interest they deserved on account of the defective nature of the means which were available for showing diseased conditions of the region in question. It has been, and is, of course, possible for a laryngoscopist to demonstrate the laryngeal image, as it were, "over his shoulder." There is practically room for the head of one observer to occupy the place of vantage and to obtain a fairly satisfactory view. But apart from such disadvantages as the Laocoon-like contortions often necessary on the part of the laryngoscopist and the more or less confused crowding, due to want of space, on the part of the observers, the method is slow, limited of application, and uncertain, and the proper demonstration of operations or manipulations within the larynx is quite out of the question. Recently Professor Meyer of Berlin has been instrumental in changing all this and he has introduced a method which will, I believe, put the subject of laryngoscopy on a new footing and will render some service to the teaching of laryngology. I have had the opportunity of making a number of experiments with an apparatus constructed (with some modifications) from the model kindly shown me at Berlin by Professor Meyer and the results of these observations have been as follows. It was found possible to show an image of the larynx, practically identical in every respect with that seen by the person examining the larynz, to as many as six observers at one time, the latter being situated at convenient distances frrom the patient, from the examiner, and from each other (Fig. 1). Also, intralaryngeal operations could be as clearly seen by the observers as by the examiner. The images were conveyed to the observers' vision by means of reflections on two circular plane mirrors, placed one on either side of the illuminating apparatus (Figs. 2 and 3). An observer situated at a distance of six or eight feet from the mirrors obtained as good an impression of the laryngeal image as a person situated close to the reflecting surfaces.
In the case of clinical meetings it has been found practicable to demonstrate laryngeal cases to about 130 observers in 20 minutes-two, three, or more observers examining at one time. In the experiments noted above most of the anatomical regions of the larynx could be FIG. 1.

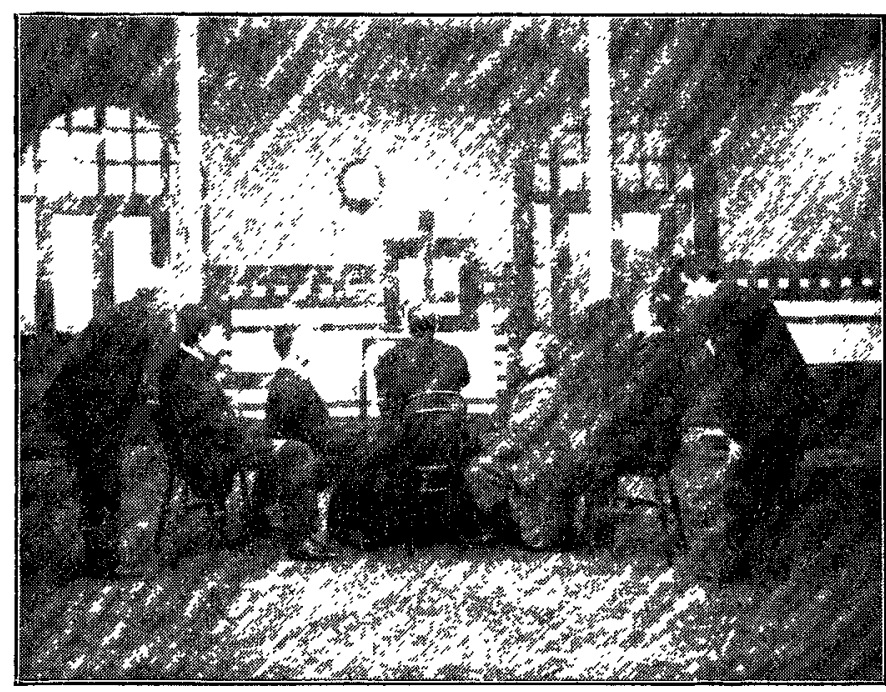

Six persons watching an intralaryngeal manipulation. The mirrors into which tbey are looking, and also the patient, are hidden, owing to the position of the examiner in the plate.

FIG 2.

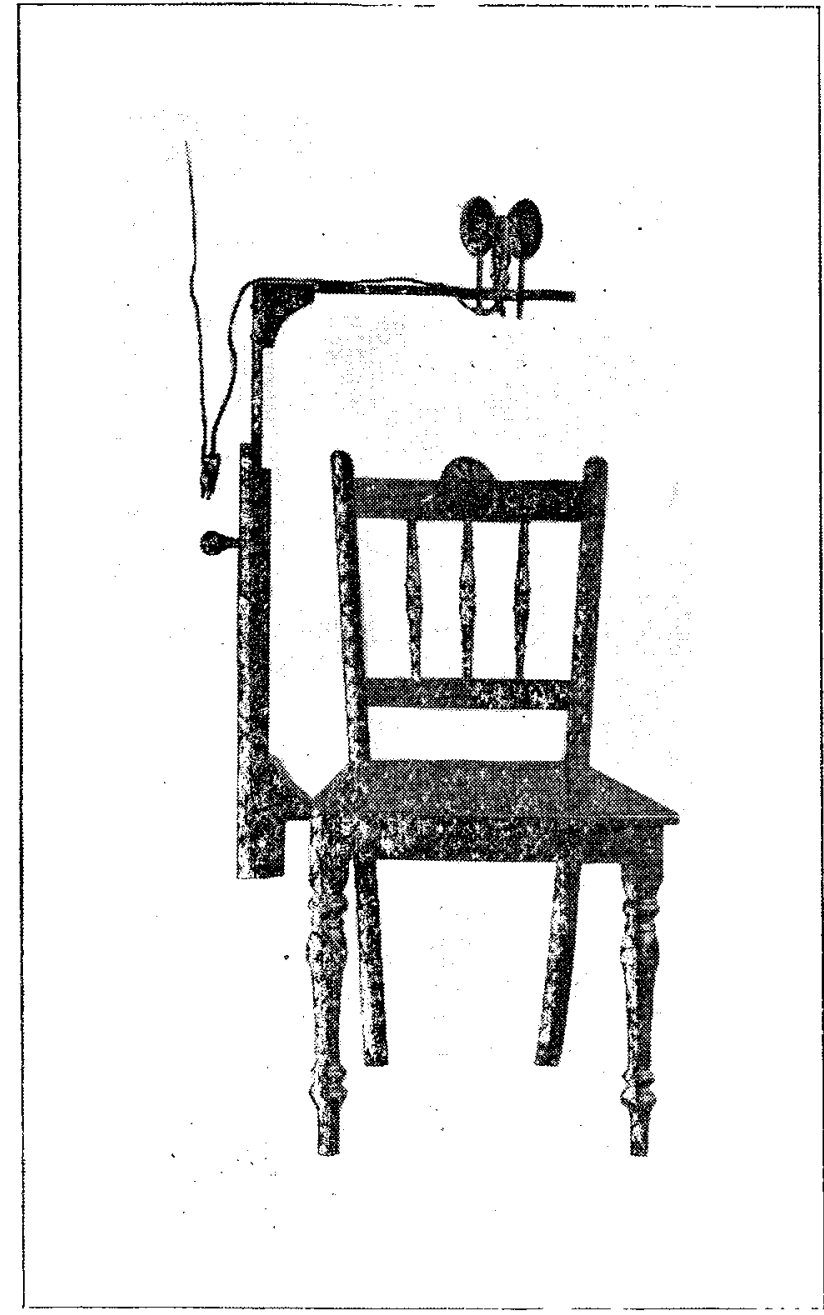

Professor Meyer's original apparatus. The chair is for the patient. On the horizontal bar are the lamp with its place at the best and to catch the laryngeal imase place at the the mirrors only are seen; the observers stane

demonstrated to the six (placed) observers by means of a laryngeal probe which was introduced, thus proving a method of teaching the topography of the larynx which had previously been possible only on specimens removed from the body. From a mechanical point of view the original apparatus 
(Fig. 2) can be briefly described as follows. There is, in the first place, a strong straight-backed wooden chair and on the right side of the seat is affixed a vertical arm. This arm is hollowed out to receive a smaller vertical arm and to this, in its turn, is attached at right angles a flat horizontal piece of wood. On that part of the horizontal piece which is nearly opposite the middle of the back of the chair (more correctly, facing the patient's mouth when he is seated in position) the laryngoscopic portion of the apparatus is placed (Fig. 2). The last-named part of the machine consists of a small electric lamp and two circular mirrors, each of the latter being three inches in diameter. Clear, unimpeded images of the larynx, or reproductions of any intralaryngeal operations which may be in progress, are reflected upon these mirrors. The examiner or operator looks through an opening in the sleeve of the electric lamp and thus gets a view of the larynx, as in the ordinary manner, except that he is only able to use one eye at a time. The inconvenience caused by this is almost negligible. The small modifications

\section{FIG. 3.}

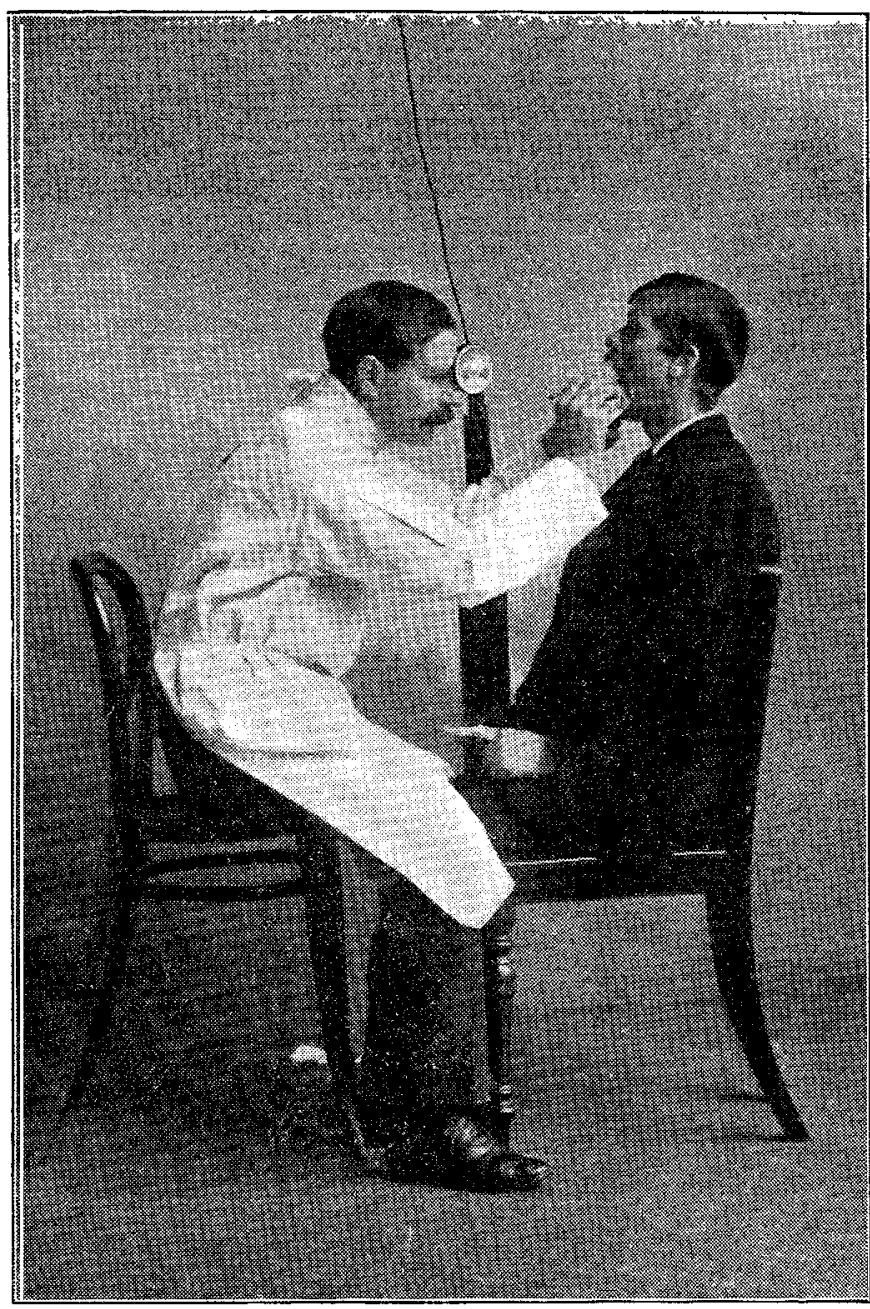

S rowing the method of examination. The light is thrown into the patient's mouth and the larrngeal image is pro jected from the laryngoscopic mirror on to two mirrors, of which is seen close to the examiner's right eye. The faint impression of the larynx, which can be seen in the plate, is clear and well illuminated in the actual apparatus.

which I have thought useful are the construction of a detachable apparatus in which the essential laryngoscopic portion can be affixed to any laryngeal lamp-holder or upright, thus rendering the machine more portable and convenient and also considerably reducing its cost. Also, I am producing an apparatus by which four laryngeal cases can be shown (if necessary in rapid succession) to a number of observers simultaneously. The apparatus has been shown to the Laryngological Society of London and at other meetings and it is, I understand, being adopted at a number of teaching hospitals. Finally, the method is not proposed to supplant, for the student, the personal examination of the larynx but rather to stimulate his interest in the subject and to supplement his practical studies. The apparatus is made (in Kngland) by Messrs. Armstrong and Brother, opticians, Deansgate, Manchester.

anchester.

\section{Clinieal 算otes:}

\section{MEDICAL, SURGICAL, OBSTETRICAL, AND THERAPEUTICAL.}

\section{A NOTE ON FIBRO-MYOMA OF THE BULBAR CONJUNCTIVA.}

By Kenneth Sco't, M.D., F.R.C.S. Edin.

CONSULTING OPHTHALMIC SURGEON, ST. MARY'S CHILDREN'S HOSPITAL, E. FORMERLY PROFESSOR OF OPHTHALMOLOGY AND OPHTHALMIC

SURGEON, KASR-EL-AINI HOSPITAL, CAIRO, EGYPT.

THE occarrence of a fibro-myoma in this position is un. usual and receives only slight passing mention in ophthalmic writings. This instance is perhaps worthy of note as the situation of the tumour involved the possibility of dangerous extension which would not only have interfered with vision but might have completely destroyed the utility of the eye, besides the ulterior risk of serious consequences connected with the fact of its very rapid and active recurrence. The growth unfortunately occurred in a medical colleague and he, probably quite correctly, associates the incidence of the tumour with an accident which happened to him while engaged in his professional duties. When he was breaking a tube of vaccine at a patient's house on August 12th of last year, a small piece of the glass flew up, struck against his right eye, and remained lodged there; it gave rise to much pain at the time and was only removed with difficulty and after considerable effort on the part of those in the house. He gave the incident no further thought until a month later, in September, when he noticed a small point of redness at the site of the recent injury in his right eye, on the sclera close to the inner edge of the cornea. This slowly increased in size and at the same time became thickened, but was not associated with pain, discomfort, or any other inflammatory symptom. There was never any question about the possibility of this being a modified form of vaccine pustule, as the lapse of time did not correspond nor did it bear the least resemblance to such an inflammation.

The patient at once sought medical advice and used the various applications prescribed, but without producing any alleviation. The local condition soon became much aggravated, the growth increasing both in area and thick ness very rapidly, so that on Oct. 12th, two months after receiving the injury, he obtained the able services of one of his friends, a surgeon, to remove the growth; this was skilfully performed with scissors and the small tumour was removed from the surface of the eyeball as completely as possible. When I had occasion to see the eye some days after this operation the wound had healed and there was only a slight redness present, limited to a portion of the sclera on the inner aspect of the globe opposite the palpebral fissure; there was no trace apparent of any extraneous morbid tissue remaining on the eye. The patient felt no local sense of irritation, there was no lacrymation, and only some tenderness of the eye on exposure to wind or to a draught of cold air.

On Nov. 28th, 47 days after the previous operation, I was consulted on account of the sudden reappearance of the growth and found that on the same site-viz., over the inner aspect of the sclera, close to the margin of the cornea and opposite the palpebral fissure, there was a very considerable accumulation of new solid tissue, upon, and closely connected with, the subjacent scleral layer; this surrounded, bot avoided covering, the area occupied by the former tumour, thus giving the appearance of there being a wide depression in its centre. The growth measured four millimetres horizontally, three millimetres in vertical diameter, and was approximately one millimetre in thickness; it was of a brownish red colour and was semi-transparent; its surface was polished and its margin was distinct and clearly defined; there was entire absence of any sign of inflammation accompanying it. Each day it showed markedly rapid increase both in size and thickness, so that on Nor. 30th I was compelled to remore it entirely.

My first incision was made in the normal conjunctiva surrounding the tumour and then by very careful and complete 